\title{
Patrimonio y resiliencia
}

Carlos Romero Moragas | Centro de Formación y Difusión, Instituto Andaluz del Patrimonio Histórico

URL de la contribución <www.iaph.es/revistaph/index.php/revistaph/article/view/3870>

El concepto de patrimonio es una construcción de las burguesías urbanas industriales capitalistas de los estados nación europeos del siglo XIX, que se democratiza e internacionaliza tras la 2. ${ }^{\text {a }}$ Guerra Mundial y se mercantiliza con la globalización neoliberal, en los 90 del pasado siglo. El capitalismo global basado en la explotación de las energía fósiles (petróleo, carbón y gas), el crecimiento ilimitado y el consumo, está tocando su techo y llegando a un punto crítico, con una doble consecuencia: de una parte el colapso del sistema económico con la consecuente quiebra de la civilización industrial y la sociedad de consumo tal como la conocemos; y de otra parte, como resultado de lo anterior, el calentamiento global, el cambio climático, la ruina ecológica y la multiplicación de los conflictos mundiales (BARNOSKY; HADLY; BASCOMPTE et ál., 2012; FERNÁNDEZ DURÁN; GONZÁLEZ REYES, 2014; TAIBO, 2016)ํ․

Las consecuencias son ya, desgraciadamente, el presente en regiones completas colapsadas, como Oriente Medio, y en nuestro denominado "cuarto mundo" donde la pobreza energética de los hogares será creciente para un gran número de población, por el incremento de los precios (TIRADO HERRERO; JIMÉNEZ MENESES; LÓPEZ FERNÁNDEZ et ál., 2016). Una de las actividades que se verá más afectada por la progresiva escasez de petróleo y la inestabilidad social va a ser sin duda el turismo y su probable drástica reducción, con importantes repercusiones para el futuro del patrimonio cultural, muy orientado a la explotación turística. También el cambio climático es ya un reto principal en la conservación física del patrimonio en numerosos lugares del planeta, como lo atestigua la misma UNESCO (MARKHAM; OSIPOVA; LAFRENZ SAMUELS et ál., 2016).

Esta descomposición del mundo tal como lo conocemos hoy día y el nacimiento de nuevos paradigmas de marcada raíz ecologista, traerán aparejados sin duda una

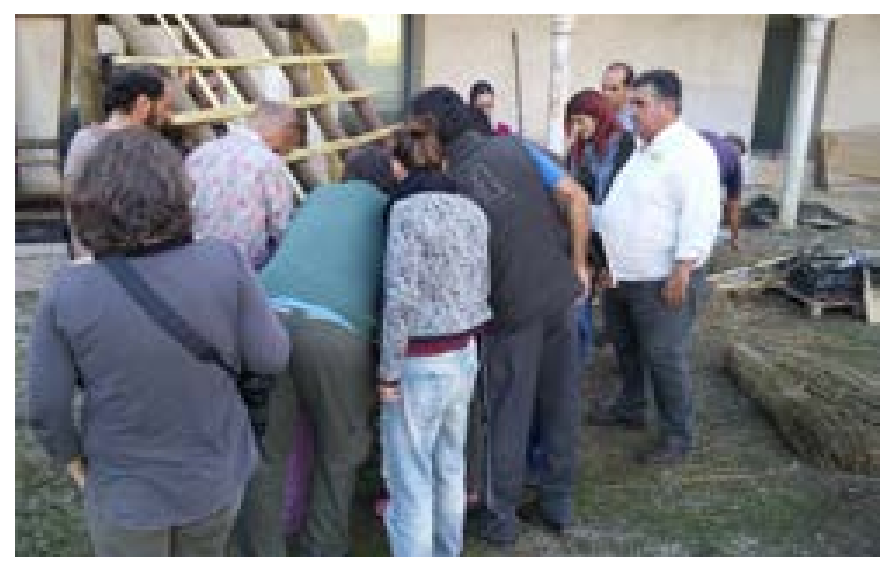

Recuperación de saberes y usos locales. Taller de cubierta vegetal, organizado por el IAPH en colaboración con la asociación cultural Hornos de la Cal de Morón | foto Fondo Gráfico IAPH

reconceptualización del patrimonio, en la que algunos elementos, hoy reconocidos como parte del mismo, estarán mejor posicionados que otros. Entre los que cobrarán valor en el futuro estarán los patrimonios que favorezcan la resiliencia, entendida como la capacidad que tiene un sistema ecológico y social para absorber o resistir alteraciones y otros factores de estrés, de tal modo que el sistema permanezca en las mismas condiciones, manteniendo en esencia su estructura y funciones, es decir la capacidad para auto-organizarse, aprender y adaptarse. Cuando mejora la capacidad de resilienciab un sistema está mejor preparado para tolerar las perturbaciones. Construir resiliencia significa ayudar a las personas y comunidades a anticiparse, preparase, enfrentarse y recuperarse del colapso o evitarlo (XU; MARINOVA; GOU, 2015). Las estrategias para construir y fortalecer la resiliencia a escala local hablan de conceptos y prácticas como el decrecimiento, la soberanía alimentaria, la agroecología, la simplicidad voluntaria, el buen vivir, y otros, que tienen en común la necesidad de abandonar la lógica productivista y la sociedad de consumo capitalista que está conduciendo al colapso. Se trata de construir alter- 
nativas desde la base, desde lo local, que garanticen las necesidades básica de subsistencia de las poblaciones y el control de los recurso de proximidad.

En este contexto de mirada hacia lo local cobra especial relevancia la autosuficiencia que posibilitan todos aquellos conocimientos y saberes tradicionales vinculados a cada territorio y comunidad, despreciados por la globalización y hoy día considerados patrimonio inmaterial. Muchos unidos a una nueva ruralidad y relacionados con la producción agroganadera (semillas autóctonas, técnicas tradicionales ecológicas, razas autóctonas... ), la bioconstrucción (materiales de proximidad, técnicas constructivas vernáculas...), las formas tradicionales comunales de manejo, uso y explotación sostenible de los territorios, la alimentación tradicional, etcétera (SOLER MONTIEL; GUERRERO QUINTERO, 2010).

Conocer, recuperar e incorporar estos saberes y usos locales, probadamente sostenibles al ser fruto de una larga interacción histórica de las comunidades con sus territorios, unido a los nuevos conocimientos que ofrecen prácticas como la permacultura, va a ir cobrando un interés creciente, que a su vez abundará en garantizar el conocimiento y conservación de una parte importante del patrimonio cultural inmaterial (CARRERA DIAZ, 2016) ${ }^{2}$.

\section{NOTAS}

1. Un apunte sobre el colapso civilizatorio se puede también leer en el manifiesto "Última llamada" elaborado en 2014 <https://ultimallamadamanifiesto.wordpress.com/ el-manifiesto/> [Consulta: 25/01/2017]

\section{A este respecto, Gema Carrera propone como terce-} ra premisa de partida de su tesis doctoral, que explora relaciones entre el patrimonio inmaterial y la resiliencia: "...considero que diversos elementos culturales considerados Patrimonio Cultural Inmaterial pueden llegar a constituirse en ejes de proyectos societarios alternativos tanto en el plano económico como en el social, ambiental, político y simbólico. En este sentido, diversos agen- tes activan procesos de patrimonialización que ponen el acento también en los valores dinámicos, simbólicos e identitarios del patrimonio cultural. En gran medida se trata de movimientos sociales que ante los efectos homogeneizadores de la globalización reaccionan ofreciendo lógicas culturales alternativas a la hegemónica no asimilables por la lógica mercantilista pudiendo constituirse en elementos de resistencia a su avance"(CARRERA DÍAZ, 2016: 25).

\section{BIBLIOGRAFÍA}

- BARNOSKY, A.D.; HADLY, E.A.; BASCOMPTE, J. et ál. (2012) Approaching a state shift in Earth's biosphere. Nature, vol. 486, junio 2012, pp 52-58 <https://www.researchgate. net/publication/235752538_Approaching_a_state_shift_in_ Earth's_biosphere> [Consulta: 25/01/2017]

- CARRERA DíAZ, G. (2016) Propuesta metodológica para la documentación y gestión del patrimonio cultural inmaterial como estrategia de desarrollo social y territorial. Tesis doctoral inédita, Universidad de Sevilla (2016) <https://idus.us.es/xmlui/ handle/11441/34477> [Consulta: 25/01/2017]

- FERNÁNDEZ DURÁN, R.; GONZÁLEZ REYES, L. (2014) En la espiral de la energía: colapso del capitalismo global y civilizatorio. Madrid: Libros en Acción / Baladre, 2014, vol. 2 <http://www.ecologistasenaccion.org//MG/pdf/en-la-espiral-dela-energia_vol-2.pdf> [Consulta: 25/01/2017]

- MARKHAM, A.; OSIPOVA, E.; LAFRENZ SAMUELS, K.; CALDAS, A. (2016) World Heritage and Tourism in a Changing Climate. United Nations Environment Programme, Nairobi, Kenya and United Nations Educational, Scientific and Cultural Organization, Paris, France, 2016 <http://whc.unesco.org/en/ activities/883/> [Consulta: 25/01/2017]

- SOLER MONTIEL, M.; GUERRERO QUINTERO, C. (2010) (coord.) Patrimonio cultural en la nueva ruralidad andaluza. Sevilla: Instituto Andaluz de Patrimonio Histórico, 2010 <http://www.iaph.es/web/canales/publicaciones/cuadernos/ cuadernos-ph/contenido/Cuadernos/CuadernoXXVI> [Consulta: 25/01/2017]

- TAIBO, C. (2016) Colapso. Capitalismo terminal, transición ecosocial, ecofascismo. Madrid: Los Libros de la Catarata, 2016

- TIRADO HERRERO, S.; JIMÉNEZ MENESES, L.; LÓPEZ FERNÁNDEZ, J. L. et ál. (2016) Pobreza, vulnerabilidad y desigualdad energética. Nuevos enfoques de análisis. Madrid: Asociación de Ciencias Ambientales, $2016<$ http:// www.niunhogarsinenergia.org/panel/uploads/documentos/ estudio\%20pobreza\%20energetica_aca_2016.pdf> [Consulta: 25/01/2017] 